Las partidas del segundo y tercer año del trienio nos muestran una realidad muy similar, mencionando distintas obras en varios molinos o en las casas que poseía el convento en Buenamesón, Ocaña o Santa María de los Llanos.

Determinar el contenido del apartado destinado a destajos puede parecer poco importante, pero la realidad es muy distinta porque, como ya hemos dicho, dentro de este capítulo figuran los nombres de dos maestros que también estaban vinculados a la fábrica del convento: Francisco de Luna y Enrique Egas. Francisco de Luna es el único que aparece mencionado todos los años: entre 1531 y 1532 cobró seis ducados, un año después recibió 7.750 maravedís y entre 1533 y 1534 recibió otros 10.000 maravedís. En el primero de los casos no se especifica la naturaleza del pago, pero en los otros dos se afirma que las cantidades se pagaban en concepto de salario. Enrique Egas sólo aparece en el apartado de destajos del último año del trienio, donde se consigna el pago de 6.000 maravedís que constituían la mitad del salario que debía recibir el maestro. Un salario que empezó a cobrar desde el día de Sant Miguell del año proximo pasado de treynta e tress ${ }^{19}$. La documentación no hace referencia al motivo concreto por el que percibían estos salarios pero, mientras no aparezcan datos que apunten en sentido contrario, parece lógico pensar que estaban relacionados con las tareas que desarrollaban en toda esa serie de obras menores que se estaban llevando a cabo en distintas posesiones del convento.

Los datos que acabamos de aportar tienen una gran importancia ya que resuelven determinadas incógnitas que hasta ahora carecían de respuesta, como la autoría del proyecto, y contribuyen a cambiar la visión que se tenía de otros aspectos, como la propia dirección de las obras. Las nuevas referencias documentales que hemos encontrado nos han desvelado el importante papel que desempeñó Enrique Egas, maestro que estuvo vinculado a la fábrica del convento prácticamente hasta la hora de su muerte. Él fue quién diseñó el proyecto y quién dirigió las obras, siendo bastante probable que a su fallecimiento fuera sustituido en esta tarea por Francisco de Luna que, como ya hemos dicho, aparece citado como maestro principal de la obra en 1538. Por otra parte, a la hora de valorar el papel que desempañaron estos dos maestros no podemos olvidarnos de la doble vinculación que mantuvieron con el convento; es decir, de su papel como maestros de la gran fábrica de Uclés y de su participación en esas otras obras que, en buena medida, estaban relacionadas con la arquitectura civil.

JoSÉ JAVIER BARRANQUERO CONTENTO

\title{
FUENTES ICONOGRÁFICAS DE LA REPRESENTACIÓN DE CRISTO DEL RELIEVE DE LA ASCENSIÓN DEL CLAUSTRO DE SILOS
}

No es algo novedoso señalar el hecho de la originalidad que presenta el relieve de la Ascensión del claustro románico de Santo Domingo de Silos a la hora de plasmar la figura de Jesús. El relieve, que es obra de finales del siglo XI del llamado primer maestro de Silos y se encuentra tallado en la cara interior izquierda del pilar sureste del claustro haciendo pendant con el relieve de Pentecostés, es en realidad la única Ascensión del arte antiguo y medieval donde Jesucristo es representado sólo por medio de su cabeza. Los autores que se han sucedido a lo largo de un siglo no han llegado a dar una explicación satisfactoria a este hecho, en el caso que se hayan preocupado de ello. El trabajo pues surge espontáneo de esta cuestión que al mirar cotidianamente el relieve nos está interrogando vehementemente. Y la respuesta surge, también espontánea, al hilo

${ }^{19}$ AHN., OOMM., Archivo Histórico de Toledo, legajo 22.968, s.f. 
de la liturgia. Mi intención con este trabajo es presentar una posible solución al por qué de esta manera originalísima y única de representar la figura de Cristo en el misterio de su Ascensión. En realidad, intento dar a conocer una serie de textos patrísticos y litúrgicos con una marcada idea teológica como fuente iconográfica de contenido que da lugar a la composición y significación del relieve. La índole, pues, de este estudio es iconográfica y, al tratarse de una obra de arte de temática cristiana, directamente teológica.

\section{Los estudios de otros autores}

Como ya hemos apuntado, la bibliografía sobre la iconografía de la Ascensión de Jesús, en general, y el claustro de Santo Domingo de Silos, en particular, no responder satisfactoriamente al interrogante que plantea esta forma de representar a Cristo. De entre los autores que la mencionan y estudian, algunos llegan a la conclusión de que esta forma de representar la Ascensión, colocando sólo la cabeza de Jesús, es una manera original y única, pero, salvo honrosas excepciones, no se han ocupado de analizar el por qué de esta iconografía, sus fuentes y significado; y, mucho menos, han llegado a explicarlo. Hagamos, ahora, pues, un somero recorrido por los más importante estudios sobre el tema.

El primero de ellos es el pionero trabajo de T. Dewald, The Iconography of Ascensión ${ }^{1}$, publicado en 1915. Aun no teniendo en cuenta esta obra el relieve de Silos, deducimos de ella que esta manera de representar a Cristo en el misterio de su Ascensión no se ajusta a ninguna de las fórmulas del arte antiguo ni medieval hasta el siglo XII, incluso posterior. No se puede asimilar a ninguno de los modelos orientales, ya sea helenístico o sirio-palestinense, que están en el origen de las formas iconográficas de representar la desaparición Cristo $^{2}$. Más concretamente, las representaciones de la Ascensión en el primer románico monumental, que derivan de las miniaturas otónidas, representan a Cristo de cuerpo entero y dentro de una mandorla, a los discípulos gesticulando y la división entre el cielo y la tierra está marcada por una línea horizontal a la mitad de la mandorla ${ }^{3}$. Si se compara con el relieve del claustro de Silos vemos que no hay ningún punto de unión. La misma conclusión sacamos al leer el trabajo de E. Mâle, L'art religieux du XII e siècle en France, sobre los orígenes de la iconografía en la Edad Media, publicado en $1922^{4}$. Pero, ciertamente, nos resulta extraño que nuestro autor tampoco tenga en cuenta la fórmula silense ya que, debido a su originalidad, hubiera sido un punto importante de referencia, como hace con otros de los relieves del mismo claustro 5 .

En el trabajo que Meyer Schapiro realiza en 1943 sobre la iconografía de la Ascensión en Inglaterra alrededor del año $1000^{6}$, detecta en las obras anglosajonas una iconografía original. Se trata del momento de la desaparición; un proceso dinámico, más que un momento estático,

\footnotetext{
1 Dewald, T., “The Iconography of Ascensión”, American Journaul of Archaeology 19 (1915) 277-319.

2 Una bibliografía básica sobre la Ascensión de Jesús se puede hallar en SCHMIDT, V.M., "Ascensione”, en Enciclopedia dell'arte medievale II, Enciclopedia Italiana, Roma 1991, 572-577.

3 Dewald, T.,"The Iconography...", 303-313.

${ }^{4}$ MÂLE, E., L'art religieux du XII e siècle en France, Armand Colin, Paris 1922.

5 En concreto, los del Entierro, el Encuentro con los discípulos de Emaús y el Árbol de Jesé; MÂLE, E., L'art religieux..., 87-92.

6 SchapIRo, M., "The Imagen of the Disappearing Christ. The Ascension in English around the Year 1000", Gazzette des Beaux-Arts, s. VI, 23 (1943) 135-152; edición española: "La Imagen de Cristo desapareciendo. La Ascensión en el arte inglés en torno al año 1000", Estudios sobre el arte de la Antigüedad tardía, el Cristianismo primitivo y la Edad Media, Alianza Forma 59, Alianza Ed., Madrid 1987, 241-259.
} 
donde sólo quedan visibles las piernas o los pies de Cristo, estando el resto tapado por una nube. No obstante, los artistas continentales de los siglos XI y XII que en las ascensiones trataron de representar la visibilidad del cuerpo de Cristo en disminución, preservaron siempre la absoluta importancia teológica de su cabeza. Es en esta corriente donde nuestro autor sitúa la Ascensión del claustro de Silos. Se trata de una representación de Cristo de tipo ideal, simbólica y teológica, que no tiene nada que ver con la experiencia óptica del fenómeno de los apóstoles que miraban desde abajo ${ }^{7}$. Luego, en 1939, en su artículo titulado Fron de Mozarabic to Romanesque in Silos se ocupará del relieve que estudiamos, pero sólo de su parte inferir, es decir, de las posibles fuentes gráficas de la distribución de los apóstoles ${ }^{8}$.

Más tarde, fray Justo Pérez de Úrbel en su libro El Claustro de Silos ${ }^{9}$, de 1955, hace una perfecta síntesis bibliográfica sobre los estudios en torno al edificio y sobre la iconografía de la Ascensión, al tratar el relieve. Sobre él puede resumir: "No es fácil inquirir el original de esta bella escena, porque el escultor ha grabado en ella fuertemente su huella personal"; y "[...] en vano trataríamos de buscarla -se refiere a la parte superior de la composición- en todo el arte anterior al siglo XI" ${ }^{10}$. Con ello, fray Justo resalta la originalidad de la composición y, especialmente, el haber representado de Cristo sólo su cabeza, rodeado por una nube que lo está tapando, pero no investiga las causas.

L. Réau en su enciclopedia sobre iconografía cristiana, publicada en $1957^{11}$ y que se nos antoja muy francesa, recoge la misma conclusión al recoger sólo la Ascensión de Silos dentro del tipo donde "sólo la cabeza de Cristo está a la vista"12.

Joaquín Yarza, en su aportación en la guía de Silos de $1973^{13}$, da un paso más pero, ni se adentra en la cuestión ni saca las consecuencias de lo que apunta. Comienza diciendo que el románico es un arte intelectual y simbólico en el que no se busca la emoción sino la ilustración. Es decir, que es un arte que, en aras del significado, cuida los aspectos compositivos y no tiene miedo de alejarse de la realidad. Luego, cuando describe el relieve, dice que de Cristo sólo se representa la cabeza, en vez del cuerpo entero o sólo sus pies, como era lo normal, y saca la siguiente conclusión final: "Se diría que el artista sacrificó la iconografía al uso en función de una composición simbólica"14. ¡Muy bien! Pero, ¿qué simbología encierra en realidad esa composición novedosa y original?

En 1990, Javier Gómez Martínez, en las Actas del congreso "El románico en Silos"15, relaciona las estructuras superiores de los relieves de la Ascensión y de Pentecostés con el "sello de Salomón". El "sello de Salomón" o "hexagrama" -estrella de seis puntas formada por la conjunción de dos triángulos equiláteros- es la figura geométrica del número seis. Se trata de un número conjuntivo por nacer de la unión del par, femenino y terrenal, y el impar, masculino y

\footnotetext{
7 SCHAPIRO, M., "The Imagen...", 245-246.

8 SchapIRo, M., "From Mozarabic to Romanesque in Silos", The Art Bulletin XXI (1939) 312-374; edición española: "Del mozárabe al románico en Silos", Estudios sobre el románico, Alianza Forma 40, Alianza Ed., Madrid 1984, 37-190.

9 Pérez de Úrbel, J., El Claustro de Silos, Ed. Aldecoa, Burgos $1955^{2}$.

10 Pérez de Úrbel, J., El Claustro..., 54.

11 RÉAU, L., Iconographie de l'art chrétien, Paris 1957.

12 RÉAU, L., Iconografía del arte cristiano. Iconografía de la Biblia. Nuevo Testamento, Tomo 1/2, Cultura Artística 5, Ed. del Serbal, Barcelona 1996, 607.

13 YARZA, J., "Silos: el claustro", AA.VV, Monasterio de Silos, Everest, León 1996, 17-54.

14 YARZA, J., "Silos: el claustro", 22.

15 Gómez Martínez, J., "Sobre el geometrismo del primer maestro silense. El "sello de Salomón" en los relieves de la Ascensión y Pentecostés”, AA.VV., El románico en Silos. IX centenario de la consagración de la iglesia y el claustro, Studia Silensia, Maior I, Abadía de Silos, Silos 1990, 587-591.
} 
celestial, marcando la oposición y, a su vez, la complementariedad entre la criatura y el creador en un equilibrio indefinido. Así, el "sello de Salomón" es un símbolo que marca la unión entre el cielo y la tierra. El relieve de la Ascensión formaría en su parte superior el triángulo equilátero con su vértice hacia arriba, y la parte superior del relieve de Pentecostés un triángulo equilátero invertido; teniendo en cuenta que los dos forman pendant, la superposición de ambos da lugar a la figura del hexagrama.

En estas mismas actas, la Dra. Malka Ben-Pechat de la universidad de Haifa, Israel, se adentra con profundidad en el estudio del significado de la iconografía de nuestro relieve. En su comunicación L'iconographie de l'Ascensión dans le programme des six bas reliefs sous une lumière theologique et liturgique ${ }^{16}$ la autora relaciona directamente la iconografía de los seis relieves del primer maestro de Silos con los dogmas católicos de la Santísima Trinidad y de la salvación del cristiano, inspirados en la liturgia según el rito mozárabe. En concreto, el relieve de la Ascensión pondría de manifiesto la consubstancialidad de las tres divinas personas, la unión hipostática de las dos naturalezas del Hijo y sería la condición del descenso del Espíritu Santo en Pentecostés como camino de salvación. También, relaciona el hecho de representar a Cristo tras las nubes, como símbolo de haber penetrado el cielo sin ser ascendido por ayuda de nadie con una homilía de san Gregorio Magno" ${ }^{17}$. Se trata de una "ascensión independiente", sin ayuda de la mano de Dios o de ángeles, donde Cristo está representado sólo por su cabeza, elemento que tiene valor emblemático.

Con posterioridad, el bello trabajo de Ch. Pellistrandi, Le Christ de Silos, de 1995, la autora se pregunta por la causa de la originalidad de la representación: "Cette tête qui couronne l'ensemble est inattendue, il est difficile de reconnaître au premier abord la scène de l'Ascension: souvent le départ du Christ est figué dans una nuée que laisseseulement apercevoir ses pieds. Ici, c'est tout le cantraire. Pourquoi?"18. Como respuesta relaciona directamente la iconografía en cuestión con el versículo 20 del capítulo 10 de la Carta a los Hebreos: "siguiendo el camino nuevo y viviente que él ha inaugurado a través de la cortina, es decir, de su propia carne" (Heb 10,20). La cabeza de Cristo, en representación de toda su persona, sería la primicia de nuestra salvación; él, entrando en la gloria, ha abierto un camino que sus discípulos deben recorrer. La imagen de la cortina de la que habla el texto bíblico, con la que se refiere a la humanidad de Cristo, daría pie al escultor para colocar esa nube que, tapa casi totalmente el cuerpo de Cristo. Pero en realidad, nos preguntamos si esta explicación, muy válida en su conjunto, sirve para explicar el por qué de colocar sólo la cabeza; ya que lo mismo hubiera valido si representa a Cristo de cuerpo entero, por ejemplo.

\section{Posibles fuentes de la iconografía de la Ascensión de Silos}

El origen de nuestra investigación debemos situarlo en la oración colecta que el Misal del Vaticano II propone para la fiesta de la Ascensión del Señor y, también, en el primer prefacio de la misma. Éstos dicen:

\footnotetext{
16 Ben-Pechat, M., "L'iconographie de l'Ascensión dnas le programme des six bas reliefs sous une lumière theologique et liturgique, AA.VV., El románico en Silos. IX centenario de la consagración de la iglesia y el claustro, Studia Silensia, Maior I, Abadía de Silos, Silos 1990, 465-471.

17 Greg. Magno, "Homilia 29”, 40 Homiliarium in Evangelia, Lib. II; Patrología Latina (PL) 76, 1216-1217. En Silos existían dos manuscritos de las 40 homilías de Gregario Magno sobre los evangelios; en la actualidad están en la Biblioteca Nacional de París (n.a.1. 2167 y 2616 A).

18 Pellistrandi,Ch., Le Christ de Silos, Un certain regard, Mame, Tournai 1995, 86.
} 


\section{—Oración colecta:}

"Fac nos, omnipotens Deus, sanctis exsultare gaudiis, et pia gratiarum actione læatari, quia Christi Filli tui ascensio est nostra provectio, et quo præcessit gloria capitis, eo spes vocatur et corporis."19

-Prefacio:

"Quia Dominus Iesus, Rex gloriæ, peccati triumphator et mortis, mirantibus Angelis, ascendit (hodie) summa cælorum, Mediator Dei et hominum, Iudex mundi Dominusque virtutum;

non ut a nostra humilitate discederet, sed ut illic confideremus, sua membra, nos subsequi quo ipse, caput nostrum principiumque, præccesit.."21
"Concédenos, Dios todopoderoso, exultar de gozo y darte gracias en esta liturgia de alabanza, porque la ascensión de Jesucristo, tu Hijo, es ya nuestra victoria, y donde nos ha precedido él, que es nuestra cabeza, esperamos llegar también como miembros de su cuerpo." 20

"Porque Jesús, el Señor, el rey de la gloria, vencedor del pecado y de la muerte, ha ascendido (hoy) ante el asombro de los ángeles a lo alto del cielo, como mediador entre Dios y los hombres, como juez de vivos y muertos.

No se ha ido para desentenderse del mundo, sino que ha querido precedernos como cabeza nuestra para que nosotros, miembros de su cuerpo, vivamos con la ardiente esperanza de seguirlo en su Reino."22

Si hemos leído atentamente, habremos observado cómo hay un término que nos remite directamente a nuestro relieve: "capitis" o "caput" (cabeza). Los dos textos se refieren a Jesucristo como "nuestra cabeza" y a nosotros como "miembros" de su "cuerpo". A simple vista, podríamos haber dicho con alto viso de seguridad que el autor de nuestro relieve pudo haber tenido como fuentes de contenido la oración colecta y el prefacio de la fiesta de la Ascensión. Pero, al consultar la bibliografía, comprobamos que tanto la oración como el prefacio son una innovación del Misal de Pablo VI, en $1970^{23}$. Por tanto, los mismos no pudieron nunca ser escuchados ni recitados por el creador de la iconografía del relieve de la Ascensión del claustro de Silos. Ante el resultado de esta primera indagación, desistir de continuar con el trabajo hubiera sido lo más normal. Pero, en realidad, hubiera sido un error. Error porque, tanto la oración como el prefacio, nos llevan a otros textos y a otras épocas más antiguos que nos abren perspectivas verdaderamente interesantes. Ya que tanto la oración como el prefacio son textos de clara inspiración patrística por su léxico y sus ideas. En su base están obras de León Magno, Agustín de Hipona y Gregorio de Nisa, que nos ilustran de cómo entendieron los cristianos primitivos la doctrina de la Iglesia como cuerpo de Cristo ${ }^{24}$.

\footnotetext{
19 Missale Romanum, Editio typica, Typis polyglottis Vaticanis, Città del Vaticano 1970, 307. Corpus orationum 330; Corpus Christianorum Latinorum (CCL) 160/L, 170. Johnson, C., "The Sources of The Roman Missal (1975). Proprium de Tempore. Proprium de Sanctis", Notitiae XXXII (1996) 71.

20 Misal Romano, Coeditores Litúrgicos, Madrid 1990, 346.

21 Missale Romanum, 410. Corpus prafationum 1295; CCL 161/C. Johnson, C., "The Sources..., 169.

22 Misal Romano, 346.

23 Johnson, C., "The Sources...", 71 y 169.

24 Urtasun, C., Las oraciones del Misal, Bib. Litúrgica 5, CPL, Barcelona 1995, 297.
} 


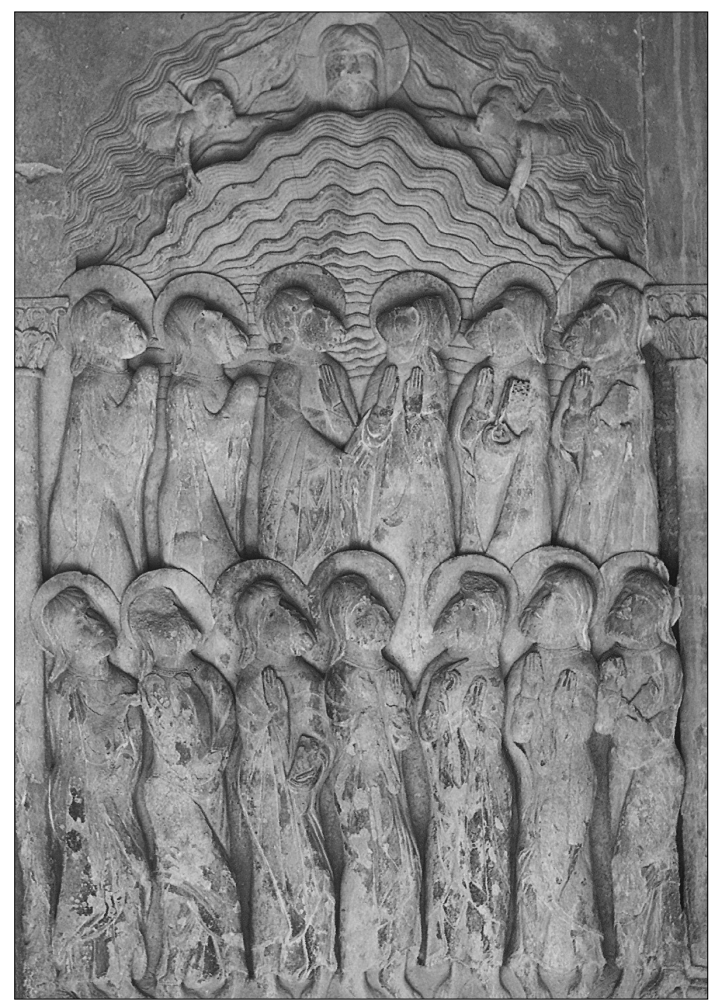

Fig. 1. Bajorrelieve de la Ascensión del Señor, siglo XI (Claustro de la Abadía de Silos).

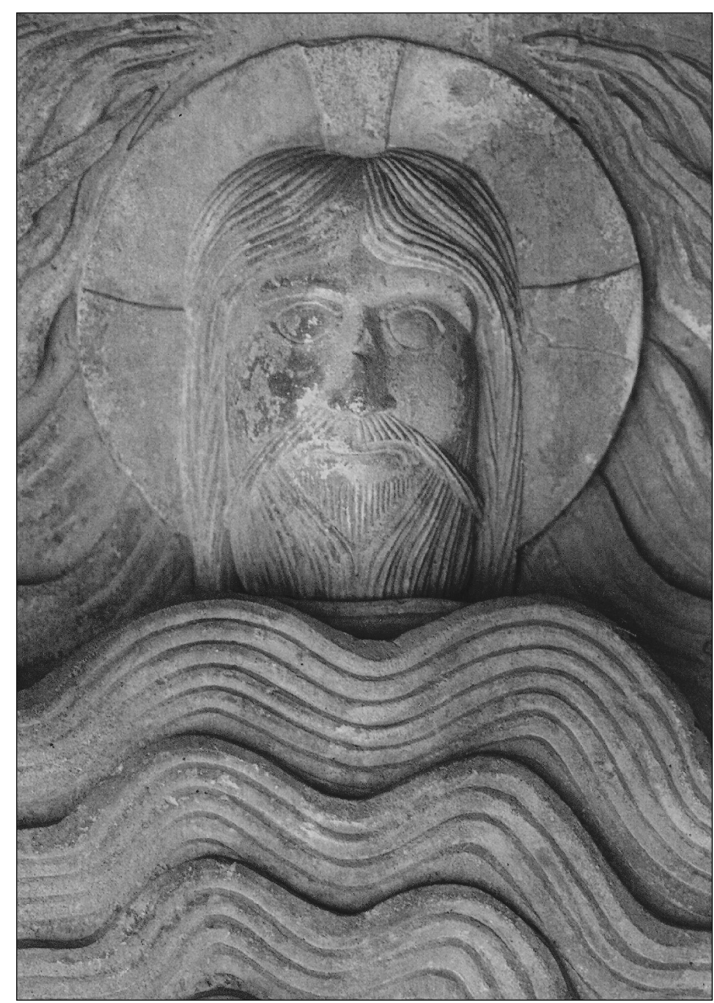

Fig. 2. Detalle de la fig. 1.

Más concretamente, lo dos textos eucológicos son una síntesis de esta eclesiología aplicada especialmente al misterio de la Ascensión de nuestro Señor Jesucristo a los cielos.

A raíz de estos primeros datos es cuando nos surgen algunas preguntas; ¿por qué se ha relacionado la doctrina de la Iglesia como cuerpo de Cristo con el misterio de la Ascensión?, ¿de dónde parte esta relación?, ¿hasta dónde llegó la influencia de la misma? y, los más importante para nosotros, ¿influyó y cómo en nuestro relieve?

\section{La doctrina de la Iglesia cuerpo de Cristo}

Para estudiar la doctrina de la Iglesia como cuerpo de Cristo debemos acudir en primer lugar a la eclesiología de Pablo de Tarso. Justamente, será la definición de la Iglesia como cuerpo de Cristo la expresión más genuina de san Pablo de su doctrina sobre la Iglesia. Se trata de una visión netamente cristocéntrica que se articula por la unión radical de los creyentes con Cristo y de los creyentes entre sí. Con respecto a esta doctrina, Pablo posee dos series de textos que se encuentran en dos grupos distintos de cartas: por una parte las grandes cartas, Romanos $(12,3-8)$ y 1 Corintios $(6,12-20 ; 12,12$ y 10,16-17), y por otra las cartas de la cautividad, Colosenses y Efesios ${ }^{25}$.

25 AnTón, A., La Iglesia de Cristo. El Israel de la Vieja y de la Nueva Alianza, Maior 15, BAC, Madrid 1977, 553-554. 
En las grandes cartas sôma significa la comunidad particular ${ }^{26}$. Ésta se presenta con la imagen de un organismo vivo, un cuerpo formado por una pluralidad de miembros que forman unidad (1Cor 12,12-27). Por su parte, en las cartas de la cautividad, que suponen un paso más en el desarrollo de esta doctrina adquiriendo ésta un lugar preponderante, tanto sôma como tó sôma tou Christou se refieren a la Iglesia universal. Si antes se hablaba que los cristianos formaban una unidad en Cristo, en estas cartas ya se expresa clara y rotundamente que la Iglesia es el cuerpo de Cristo (Col 1,18.24 y Ef 1,23). Se trata de una personificación que le da un mayor protagonismo y singularidad frente a la pluralidad de las iglesias locales. Por cuerpo de Cristo se entiende ahora sobre todo la relación de la Iglesia con Cristo ${ }^{27}$. Relación que marca también una más nítida distinción entre el Cristo individual y el cuerpo eclesial. Esta distinción se expresa por medio de la relación que se establece entre sôma y kephalê: "Y él es la cabeza del cuerpo, de la Iglesia" $(\mathrm{Col} 1,18)^{28}$. Mientras que en 1Cor 12,21 la cabeza en un miembro más del cuerpo, en Efesios y Colosenses designa al jefe único. Cristo como cabeza se sitúa por encima de todas las fuerzas cósmicas y, así, como el que tiene autoridad sobre el cuerpo, no sólo para dominarlo sino, también, para darle vida y sustento. Pero, ¿dónde podemos encontrar la relación entre esta eclesiología y la Ascensión de Cristo? Debemos seguir adentrándonos; en concreto en la Carta a los Efesios.

Efectivamente, en Efesios, escrita poco después que Colosenses, su autor quiere dejar clara la primacía incondicional de Cristo que algunos de la comunidad ponen en duda. Así, tomando como base el himno cristológico de la Carta a los Colosenses (1,15-20), describe la soberanía cósmica de Cristo: "«sometió todo bajo sus pies»; y lo dio, como cabeza suprema, a la Iglesia, que es su cuerpo" (Ef 1, 22-23a). Como se puede observar, el autor utiliza la imagen de la cabeza para describir esta soberanía. Cristo, cabeza de la Iglesia, se une a su esposa, la única Iglesia que él construye como cuerpo suyo, y le da vida. En ella inicia su señorío por medio del cual reina sobre todo el universo. Y justamente esta acción de Dios da comienzo cuando Cristo fue exaltado a la derecha de Dios, por encima de los poderes y autoridades $(1,20-21)^{29}$. El texto paulino dice: "conforme a la energía de la fuerza poderosa que desplegó en Cristo al resucitarlo de entre los muertos y sentarlo a su derecha en los cielos..., "«sometió todo bajo sus pies»; y lo dio, como cabeza suprema, a la Iglesia, que es su cuerpo, lo que está lleno de quien llena el universo de todo" $(1,20-23)$. Es decir, Cristo fue constituido como cabeza de la Iglesia y soberano de todo lo creado al ser resucitado y sentado a la derecha del Dios en la gloria del Padre, por haber culminado en la tierra la obra de la encarnación (Ef 4,3-16).

Aquí, pues, es donde está el motivo de la unión entre la imagen de Cristo como cabeza de su cuerpo y su Ascensión a los cielos, ya que el misterio que se denomina en las escrituras como exaltación o "sentar a la derecha en los cielos" se asimila y se expresa por medio de la imagen plástica de la Ascensión. Hablando de forma plástica, según nos lo narran algunos escritos bíblicos, la exaltación de Cristo, que comenzó el día de Pascua, se hizo definitiva y totalmente manifiesta el día de la Ascensión. Entonces la victoria fue completa. Y esta victoria lo constituye en cabeza de un cuerpo, la Iglesia, que por esta indisoluble unión participa ya de su misma gloria ${ }^{30}$.

\section{El desarrollo de los Padre de la Iglesia}

Siguiendo las huellas de Pablo muchos padres de la Iglesia han utilizado la imagen del cuerpo para hablar de la Iglesia. Pero, tendremos que esperar a san Agustín de Hipona para ver establecida y desarrollada la relación entre el misterio de la exaltación de Jesús a la gloria de Dios y

\footnotetext{
26 SCHLIER, H., La carta a los Efesios. Comentarios, Biblioteca de Estudio Bíblicos, Sígueme, Salamanca 1991, 117.

27 SCHLIER, H., La carta a los Efesios..., 117-118.

28 AnTón, A., La Iglesia de Cristo..., 563-565.

29 SCHLIER, H., La carta a los Efesios..., 85.

30 Ryan, V., Pascua-Fiestas del Señor, Alba, Minor 8, Paulinas, Madrid 1987, 60-62.
} 
la teología de la Iglesia como cuerpo. No se trata ya de referencias más o menos implícitas sino de un discurso nítido donde con diafanidad se aprecia la relación que se establece entre ambas realidades. Tras san Agustín, san León Magno tomará y plasmará también esta idea.

En la obra de san Agustín de Hipona (354-430) ${ }^{31}$, observamos el gran predicamento que tiene la eclesiología del cuerpo místico. El doctor de Hipona considera a la Iglesia, a la manera de san Pablo, como un organismo vivo formado por una cabeza y un cuerpo con diversos miembros. Esta unidad de cabeza y miembros desarrolla una verdadera corriente de solidaridad entre el cielo y la tierra que no deja indefenso a los cristianos. Una solidaridad que debe darse igualmente entre los miembros del cuerpo. Pero, será en algunos de sus escritos donde hace referencia a la Ascensión o en sermones para esta fiesta donde veamos establecida claramente la relación entre las dos doctrinas. Los textos son los siguiente: El Sermón 53 A, sobre Las Bienaventuranzas, donde comenta Mt 25,40: "Ahora, en cambio, Cristo no necesita de nadie, pues colocó su carne incorruptible a la derecha del Padre. ¿Cómo voy a darle aquí a él que nada necesita? ¿Se te pasa por alto lo que dijo: Lo que hicisteis a uno de estos pequeños mío, a mí me lo hicisteis? La cabeza está en el cielo, pero tiene los miembros en la tierra" ${ }^{32}$. El estudio sobre el Salmo 56 de las Enarraciones sobre los Salmos: "Ahora, hermanos hemos oído en el evangelio ${ }^{33}$ cuánto nos ama el Señor y Salvador nuestro, Jesucristo, Dios con el Padre y hombre con nosotros, que se ausentó de nosotros y ya está sentado a la derecha del Padre. [...] El Cristo total es cabeza y cuerpo, lo que no dudo que vosotros ya sabéis; la cabeza es nuestro Salvador, que padeció debajo del poder de Poncio Pilato y que ahora, después de resucitar de entre los muertos, está sentado a la diestra de Dios Padre; su cuerpo es la Iglesia, no ésta o aquella, sino la difundida por el orbe; [...] Esta Iglesia, que consta de todos los fieles, por que todos ellos son miembros de Cristo, tiene su cabeza colocada en el cielo, la cual gobierna a su cuerpo, el cual, aunque esté separado de la visión, está unido por la caridad" 34 . El Tratado 105 sobre el evangelio de san Juan: "Y si el Apóstol ha dicho de nosotros: "Como nos eligió antes de la formación del mundo», ¿por qué no ha de ser verdad que el Padre glorificó a nuestra cabeza en aquel momento en que por Él nos eligió a nosotros por miembros suyos?"35. El Sermón 263 A sobre La Ascensión del Señor: "Él ha sido ensalzado ya por encima de los cielos; no obstante, sufre en la tierra cuantas fatigas padecemos nosotros en cuanto miembros suyos." 36 [...] "No hemos de perder la esperanza de alcanzar la perfecta y angélica morada celestial porque él haya dicho: Nadie sube al cielo sino quien bajó del cielo: el hijo del hombre que está en

\footnotetext{
31 Para los textos en castellano de san Agustín hemos utilizado la edición de la BAC, Obras completas de San Agustín, preparada por varios autores agustinos españoles.

32 AA.VV., Obras completas de San Agustín, BAC 441, Madrid 1983, 93. "Modo Christus nullius indiget, incorruptibilem carnem ad Patris dexteram collocavit. Quomodo ei hic do non egenti? Excidit quod ait: quod uni ex minimis meis fecistis, mihi fecistis (Mt 25,40). Caput in cælo est, sed membra habet in terra"; Aug., Sermo 53 A (Morin 11), 6; PLS 2, 678.

${ }^{33}$ Cf. Jn 15,12: "Nadie tiene amor más grande que el que da la vida por sus amigos".

34 Obras completas..., BAC 246, Madrid 1965, 393. "Audimus in Evangelio modo, fratres, quamtum nos diligat Dominus et Salvator noster Iesus Christus, Deus apud Patrem, homo apud nos, ex nobis ipsis, iam circa dexteram Patri, audisti quantum nos diligat. [...] Et quoniam totus Christus caput est et corpus, quod bene vos nosse non dubito: caput est ipse Salvator noster, passus sub Pontio Pilato, qui nunc postea quam resurrexit a mortuis, sedet ad dexteram Patris: corpus autem eius est Ecclesia; nos iste, aut illa, sed toto orbe diffusa; [...] Tota enim Eccleia constans ex omnibus fidelibus, quia fideles omnes membra sunt Christi, habet illud caput positum in cælis quod gubernat corpus suum; etsi separatum est visione, sed annectitur charitate.”; AUG, Enarra. Ps 56, 1; PL 36, 661. En la misma línea abunda la Exposición 10 sobre la primera Carta de san Juan, 9; PL 35, 2062.

35 Obras completas..., BAC 165, Madrid 1957, 600. "Si enim de nobis dixit Apostolus, Sicut elegit nos in ipso ante mundi constitutionem; cur abhorrere putatur a vero, si tunc Pater caput nostrum glorificavit, quando nos in ipso, ut membra eius essemus, elegit?"; AUG, In Ioh. tract. 105, 7; PL 35, 1907.

36 Obras completas..., BAC 447, Madrid 1983, 659. "Ille iam exaltatus est super cælos; patitur tamen in terris quicquid laborum nos tamquam eis membra sentimus.”; AUG., Sermo 263 A, 1; PLS 2, 494.
} 
el cielo. [...] Pero tales palabras se dijeron en atención a la unidad que formamos, según la cual él es nuestra cabeza y nosotros su cuerpo... A Cristo, pues, lo constituyen muchos miembros, que son un único cuerpo" 37 . El Sermón 265, el quinto sobre La Ascensión del Señor: "Después que, llenos de asombro, le vieron ascender y se alegraron de que subiera a lo alto -el que la cabeza vaya delante es garantía para los miembros-, escucharon también la voz de los ángeles..."38. Y el Sermón 395, el sexto sobre la Ascensión del Señor, explica: "Por tanto, si descendió hasta nosotros, nos elevó. Nuestra cabeza nos ha elevado ya en su cuerpo; donde está él le siguen también los miembros, puesto que donde se ha dirigido antes la cabeza han de seguirle también los miembros. Él es la cabeza, nosotros somos los miembros. Él está en el cielo nosotros en la tierra"39.

Tras san Agustín y sin duda influenciado por el africano, será la pluma del papa León Magno (pont. 440-461) la que mejor resuma, en un fragmento de la Homilía 1 sobre la Ascensión del Señor, la relación que estamos estudiando. El texto en concreto dice: "Y ciertamente había motivo de extraordinaria e inefable exultación al ver cómo, en presencia de aquella santa multitud, una naturaleza humana subía sobre la dignidad de todas las criaturas celestiales, elevándose sobre los órdenes de los ángeles y a más altura que los arcángeles, no teniendo ningún límite su exultación, ya que, recibida por su eterno Padre, era asociada en el trono a la gloria de Aquel cuya naturaleza estaba unida con el Hijo, ya que la ascensión de Cristo es nuestra elevación, y el cuerpo tiene la esperanza de estar algún día donde le ha precedido su gloriosa cabeza; por eso, con dignos sentimientos de júbilo, amadísimos, alegrémonos y gocémonos con piadosas acciones de gracias" 40 . Podemos comprobar fácilmente la influencia directa que existe entre el texto de san León y la oración colecta actual de la fiesta.

\section{-Oración colecta:}

"Fac nos, omnipotens Deus, sanctis exsultare gaudiis, et pia gratiarum actione lætari, quia Christi Filli tui ascensio est nostra provectio, et quo præcessit gloria capitis, eo spes vocatur et corporis".
—Sermón 73 de san León:

"Quia igitur Christi ascensio, nostra provectio est, et quo præcessit gloria capitis, eo spes vocatur et corporis, dignis, dilectissimi, exsultemus gaudiis, et pia gratiarum actione lætemur".

Resumiendo, podemos concluir que la relación entre la imagen de la Iglesia como un cuerpo y la Ascensión de Cristo, que tiene su origen en san Pablo, se desarrolla ampliamente en los Padres, especialmente en Agustín de Hipona y el papa León Magno. Sus tratados y homilías fueron guardados celosamente en las bibliotecas, en donde se leyeron y meditaron para un ulterior desarrollo.

37 Obras completas..., BAC 447, Madrid 1983, 660-661. "Neque enim propterea nobis desperanda est perfecta et angelica cælestis habitatio, quia dixit, nemo ascendit in calum, nisi qui de calo descendit, filius hominis qui est in caelo: [...] sed dictum est propter unitatem, quia caput nostrum est, et nos corpus eius."; Aug., Sermo 263 A, 2; PLS 2, 495.

38 Obras completas..., BAC 447, Madrid 1983, 680. "Tunc ergo postea quam id quod videbant ascendere mirabantur, sursum tamen ire gaudebant; capitis enim pracessio, spes membrorum est; audierunt et angelica vocem:"; Aug., Sermo 265, De Ascensioni Domini 5, 2; PL 38, 1218. Nótese que utiliza la palabra pracessio, expresión que utilizará León Magno y que recogerá la colecta de la Ascensión.

39 Obras completas..., BAC 461, Madrid 1985, 536. "Si ergo descendit ad nos, levavit nos. Iam in corpore suo levavit nos caput nostrum: ubi est, sequentur et membra. Quia quo pracessit caput, secutura sunt membra. Ille est caput, nos sumus membra. In cælo est ille, nos in terra.”; Aug., Sermo 395, De Ascensione Domini, 6, 2; PL 39, 1716. Nótese el uso de pracessit como en el sermón anterior.

40 Leo. M., Sermo 73, De Ascensione Domini sermo 1, 292; PL 54, 396. Como hemos hecho notar (notas 39 y 40), León Magno utiliza la misma expresión que Agustín para indicar que Cristo precede, precessit, a los miembros de su cuerpo. 


\section{Repercusión de la temática en los libros litúrgicos}

Uno de los ámbitos donde estos escritos de los Padres tuvieron más aplicación y desarrollo fue la liturgia, el culto cristiano; y especialmente como homilías y fórmulas oracionales ${ }^{41}$.

- Las homilías: Los escritos de los Padres, con el paso del tiempo y las necesidades litúrgicas, se fueron compilando y seleccionando en libros para su utilización en las distintas celebraciones. Así nacieron los homiliarios, de los cuales se leía el comentario del segundo nocturno del oficio de vigilias. Se conservan un número considerable de estos códices repartidos por los distintos archivos y bibliotecas. Ellos están compuestos según los distintos tiempo litúrgicos y las fiestas del Señor y de los santos que en ellos se celebraban. Al centrarnos en el caso del monasterio de Silos vemos que se conservan tres de estos homiliarios. Son manuscritos de finales del siglo XI y principios del XII: el Homiliario visigótico que se conserva en Londres (British Library, Add. 30853$)^{42}$ y los dos Homiliarios romanos de la Biblioteca Nacional de París (N.a.l. 2176 y N.a.l. 2177) ${ }^{43}$.

El Homiliario de Londres es un manuscrito copiado en el escriptorio de Silos o de San Millán de la Cogolla, a finales del siglo XI (después de 108044), y es el mejor exponente de colección de homilías de la liturgia hispánica. Para el día de la Ascensión (fol. 83 y 84), designa un sermón que, según Morin ${ }^{45}$, tiene gran afinidad con la Homilía 265, la quinta sobre la Ascensión del Señor, de san Agustín ${ }^{46}$. Pero, ciertamente, cuando leemos el manuscrito original comprobamos que no se recoge el texto concreto que nos interesa.

El Homiliario N.a.l. 2176 de París es un manuscrito incompleto de finales del siglo XI que contiene las homilías para el oficio de las vigilias monásticas del rito romano, que guarda relación con el otro homiliario de Silos de esta misma biblioteca (N.a.l. 2177) ${ }^{47}$. Si analizamos sus páginas, vemos que en los folios 340 y 343 designa para la vigilia de la fiesta de la Ascensión del Señor el Tratado 105 sobre el Evangelio de san Juan de san Agustín de Hipona ${ }^{48}$. Se trata de uno de los textos que hemos traído en el apartado anterior ${ }^{49}$.

\footnotetext{
41 Junto al análisis de las homilías y las oraciones, estudiamos también los prefacios, (que son otras fórmulas eucológicas de acción de gracias que se recitan sólo dentro de la eucaristía), pero la búsqueda no dio resultado positivo.

42 Morin, G., Liber Comicus sive lectionaius Missa quo Toletana Ecclesia ante annos mille et ducento utebatur, Maredsous 1893, 406-425.

43 ETAIX, R., "Homiliaires wisigothiques provenants de Silos à la Bibliothèque nationale de Paris", Hispania sacra XII (1959) 213-224. En la fol. 265 del N.a.l. 2176 se encuentra el dibujo de la Visitatio sepulcri que influyó claramente en la composición del relieve de la Depositio y la Visitatio sepulcri de nuestro claustro; cf. MoraLEJo, S.,"El claustro de Silos y el arte de los caminos de peregrinación", AA.VV., El románico en Silos. IX centenario de la consagración de la iglesia y el claustro, Studia Silensia, Serie Maior I, Abadía de Silos, Silos 1990, 209-210.

44 Cf. Vivancos, M., Glosas y notas marginales de los manuscritos visigóticos del Monasterio de Santo Domingo de Silos, Studia Silensia XIX, Abadía de Silos, Silos 1996, 164-165.

45 Morin, G., Liber Comicus..., 414.

46 Homiliario visigótico, BL, Add 30853, f. 83; MuIR WhithehILL, W., "The manuscripts..., 286. Uno de los sermones del santo exponente de la relación que estudiamos.

47 Vivancos, M., "Glosas...", 265-266.

48 AUG., In Ioh. tract. 105; PL 35, 1904-1908. En realidad, el manuscrito, según los estudios de Etaix, se basa para su ordenación en el compendio de homilías que hace Pedro Diácono en su Homiliarius; en concreto se trata de la Homilía 142, "In vig. Ascensionis", de entre las homilías "de Tempore"; PL 95, 1339. Pero, el estudio de Etaix trae la numeración de los homilías que hace LECLERCQ, J., su trabajo Tables pour l'inventaire des homiliaires manuscrits, en la revista "Scriptorium" II, 2 (1948) 195-214, donde a esta homilía le corresponde la signatura PD II, 25.

49 En concreto, en el fol. 341, col. 1, líneas 24-28, se encuentra escrito: Sic enim dixit apostolus, sicut enim elegit nos in ipso ante mundi constitutionem cur $\mathrm{ab}[\mathrm{h}$ ] orre putatur a vero si tunc pater [c]aput nostrum glorificavit quando nos in ipso ut membra ei[u]s essem elegit.
} 
Y este mismo códice, en el folio 344, designa como homilía para el día de la Ascensión el Sermón 73, De Ascensione Domini 1, de san León Magno ${ }^{50}$; sermón clave, entre los que hemos señalado en el apartado anterior, para entender la relación que estamos estudiando ${ }^{51}$.

Estos dos ejemplos nos muestran claramente cómo los monjes de Silos de finales del siglo XI y principios del XII, época del inicio de la construcción del claustro románico, tenían una primera fuente en las homilías de los Padres para conocer la relación que éstos establecen entre el misterio de la Ascensión y la teología del cuerpo místico.

- Las oraciones: Otro elemento de la liturgia que debemos analizar son las oraciones, fórmulas cortas de petición e invocación que de forma y número variable se extienden a lo largo de las celebraciones de los distintos ritos. Las oraciones fueron elaboradas por los pastores por falta de formularios fijos. Sin duda, estas composiciones están influenciadas no sólo por las Sagradas Escrituras sino por la teología elaborada por los Padres de la Iglesia. De ahí, que en ellas podamos encontrar rastros de la relación que estamos estudiando. Las oraciones las podemos encontrar en distintos libros litúrgicos como los oracionales, los misales y los breviarios, que en cada rito pueden recibir una denominación diferente.

A la hora de adentrarnos en el análisis de las oraciones para nuestro trabajo, hemos buscado directamente las fórmulas correspondientes a los días de la Ascensión, de su vigilia o del domingo posterior a ella, entre las correspondientes a la liturgia mozárabe - rito que se celebraba en Silos hasta finales del siglo XI-y, luego, entre los manuscritos más antiguos de la romana. Del primero de los ritos hemos encontrado tres oraciones que contiene en su redacción el tema que estamos estudiando.

"Domine Iesu, qui ascendisti super cælos cælorum ad orientem, occasum nostrum tuo occasu devincens, quos in te suscepisti redimendos, in te perfice ad excelsa tollendos; ut ubi caput præcessisti glorificatum, illic totum corpus adtrahas honorandum; nec in occiduum mundi relinquas, quos ad orientem perpetuum verus triumphator exaltas." 52

"Domine rex gloriæ, qui patefactis et impletis profetarum oraculis, tanquam eleuatis æternalibus portis paternam repetis sedem; quia dum tua Deitas eo, quo numquam discessit, regreditur, humano generi cælorum aditus aperitu: dona, ut illic extendatur nostra intentio, quo præcessit tua redemtio; nec inhereamus captiua delectatione terrenis, quum iam nostri corporis caput tecum regnet in cælis." 53

"Domine, qui exaltas cornum Christi tui, domini videlicet ac redemptoris nostri, cum eum ad cælos, unde venerat, videntibus apostolis corporaliter euexisti: præsta, quæsumus, ut nos, quos miserando membra eius fieri elegisti, illic cum beati sequi mereamur post transitum, quo ipse caput nostrum præcessit præ omnibus gloriosum." 54

Las tres oraciones las encontramos en los oracionales u Orationes sanctae, además de en un breviario. En concreto, la primera, "Domine Iesu, qui ascendisti", está en el códice 89 de la Biblioteca Capitular de Verona ${ }^{55}$. La segunda, "Domine rex gloriæ", además de en el códice de Verona, está en dos manuscritos de la British Library de Londres: un Orationes sanctae, el Add. 3085256,

50 PL 94, 394-96. Según Pedro Diácono: PL 95, 1340; y según Leclercq: PD II, 26.

51 Más concretamente, en el fol. $344 \mathrm{v}^{\mathrm{O}}$, col. 1, líneas 3-7, se puede leer: Q[u]ia igitur xpi ascensio nostra profectio est et quo processit gloria capitis eo spe[s] subducatur et corporis dignis dilectisimi et exultemus gaudiis et pia gratiarum actione letemur.

52 Oracional Visigótico 1001; VIVEs, J., Oracional Visigótico, Monumenta Hispaniæ Sacra,(serie litúrgica I, CSIC, Barcelona 1946, 323.

53 Oracional Visigótico 1011; Vives, J., 327. B.L. Add. 30846, fol. 112 vo.

54 Oracional Visigótico 1019; VIVES, J., 329. B.L. Add. 30846, fol. $123 \mathrm{v}^{\mathrm{O}}$.

55 Orationes sanctee visigótico del siglo VIII que contiene oraciones para el oficio divino; BIANCHINI, J., Libellus orationum, Roma 1741, y VIVES, J., Oracional Visigótico.

56 Orationes sancte visigótico del siglo IX que reúne una colección incompleta de oraciones desde Adviento hasta la Natividad de san Juan Bautista. Es una recensión del oracional de Verona, que perteneció al Monasterio de Silos; Vives, J., Oracional Visigótico; WhithehILl, W.M., "The manuscripts of Santo domingo de Silos", AA.VV., Homenaje a Fray Justo Pérez de Úrbel, O.S.B. 1, Studia Silensia III, Abadía de Silos, Silos 1976, 280. 
y el Breviarium Toletanum cum paucis missis, el Add. 30846,57. La tercera oración que traemos, "Domine, qui exaltas", sólo está en los dos códices de Londres citados. Como dato importantísimo para nuestro estudio, debemos señalar que tanto el manuscrito Add. 30852 como el Add. 30846 de la British Library pertenecieron hasta su subasta al monasterio de Santo Domingo de Silos. Es decir, que los monjes de Silos poseían desde el siglo IX manuscritos con oraciones para el día de la Ascensión del Señor que relacionan el misterio de esta fiesta con la imagen de Cristo como cabeza de su cuerpo.

Luego, de la liturgia romana hemos encontrado estas oraciones con la idea que nos ocupa:

"Da, quæsumus, omnipotens Deus, illuc subsequi tuorum membra fidelium, quo caput nostrum principiumque præcessit." 58

"Exaudi nos, Deus salutaris noster, ut per hæc sacrosancta mysteria in totius ecclesiæ confidamus corpore faciendum, quod eius præcessit in capite." 59

"Præsta, quæsumus, omnipotens Deus, ut per hæc sacrosancta commercia in totius ecclessiæ confidamus corpore faciendum, quod eius præcessit in capite." 60

Como se puede observar, estas fórmulas oracionales romanas, al igual que las mozárabes, poseen en común la eclesiología del cuerpo místico basada directamente en las homilías de san Agustín y en el Sermón 73, el primero sobre la Ascensión, de san León Magno. Esta influencia, común a las seis oraciones, la vemos en el uso de la fórmula pracessit, perfecto del verbo latino praecedo, que utilizan los dos padres. Además, de las palabras corpus, membra y caput.

Ninguna de estas oraciones romanas se hallan en los manuscritos que aún existen de los pertenecientes a Silos pero, con toda seguridad, algunas de estas fórmulas eucológicas estaban transcritas en los misales o breviarios que la comunidad de finales del XI y principio del XII utilizaba para la liturgia diaria. Es de suponer que estas oraciones eran conocidas por los monjes de Silos $\mathrm{y}$, por tanto, recitadas y escuchadas en la liturgia.

\section{Conclusiones}

Hasta aquí se extiende la exposición de la investigación realizada en torno a las distintas fuentes escriturísticas, patrísticas y litúrgicas que a nuestro modo de ver están detrás de la originalidad que presenta la iconografía del relieve de la Ascensión del claustro de Silos. A raíz de lo expuesto pienso que podemos sacar algunas conclusiones.

La relación entre la eclesiología del cuerpo místico, basada en la imagen de un cuerpo con cabeza y miembros, y la glorificación de Jesucristo por el Padre -acontecimiento que se expresa por medio de la escena de la Ascensión-, es una realidad que parte ya del mismo san Pablo y está presente en la Carta a los Efesios. Esta relación entre las dos ideas teológicas no es algo que se quede en el epistolario paulino sino que tiene su repercusión y desarrollo en los escritos de los Padres de la Iglesia, especialmente Agustín de Hipona y León Magno.

De igual manera, esta teología paulina desarrollada por los Padres de la Iglesia influyó decisivamente en el contenido y diseño de la liturgia del día de la Ascensión. Una influencia que vemos en distintos formularios para los distintos ritos. Todos ellos utilizan la imagen de Cristo como cabeza de un cuerpo formado por muchos miembros unidos. Pero lo más importante para nuestra

\footnotetext{
57 Se trata del Brevierium Toletanum cum paucis missis, manuscrito mozárabe de finales del siglo XI que contiene los oficios y las misas desde Pascua a Pentecostés; WhithehILL, W.M., "The manuscripts...", 288.

58 Corpus orationum 1008; CCL 160/A, 72.

59 Corpus orationum 2505; CCL 160/C, 64.

60 Corpus orationum 4508; CCL 160/F, 96.
} 
investigación es haber encontrado estos textos litúrgicos en los manuscritos que se utilizaban para los ritos -mozárabe y romano- de la época en que se estaba construyendo el claustro de Silos. Más aún, el mismo monasterio poseía libros litúrgicos que contenían estos formularios.

Como idea central del trabajo, pienso que, aunque lo expuesto no nos llevan a demostrar que el autor o diseñador de la iconografía de la Ascensión de Silos tuvo como fuente de contenido las homilías de los Padres y las oraciones de la liturgia designadas para la fiesta de la Ascensión del Señor, sí es una posibilidad muy probable. El responsable de haber representado al Cristo de la Ascensión sólo por su cabeza pudo muy bien haberse inspirado en los textos litúrgicos que recitaba y escuchaba en las celebraciones cada año. Aunque, como hemos visto, los textos no son originales de Silos y en cualquier lugar donde se recitasen hubiera podido surgir esta iconografía, pudo ser que el artista de Silos, sin dejar de estar influenciado por ciertas fuentes gráficas de las representaciones de su época y anteriores, fuera más sensible y perspicaz, más original y avispado para idear una nueva iconografía a partir de un contenido teológico contenido en la liturgia. No se conformó con representar el hecho, de forma más o menos real e histórica basado en los relatos evangélicos y del libro de los Hechos de los Apóstoles, sino que, imbuido de la teología concreta que surge de los textos patrísticos y litúrgicos, idea una nueva y única forma de representar la Ascensión de Jesucristo a los cielos.

Creo que no resulta descabellado presentar esta hipótesis. La liturgia y sus textos son una fuente riquísima de inspiración; los eclesiásticos y especialmente los monjes estaban imbuidos de su vasto contenido; los manuscritos litúrgicos eran frecuentemente fuente gráfica de inspiración..., ¿cómo no pudieron ser estas oraciones, trascritas en los propios manuscritos de Silos, fuente de inspiración para el relieve de la Ascensión, máxime cuando uno de estos manuscritos, -el códice N.a.l. 2176 (fol. 265) de la BNP-, es con uno de sus dibujos, fuente de inspiración gráfica del relieve de la Depositio y la visitatio sepulcri de nuestro claustro, obra del mismo taller o autor ${ }^{61}$. Recordemos cómo autores, como M. Schapiro, Ben-Pechat y Ch. Pellistrandi, citados en este trabajo, vieron también en los textos patrísticos y litúrgicos la fuente de nueva iconografías. De esta manera, creemos haber hallado la solución al problema que surge de la original manera de representar al Cristo de la Ascensión en el primer relieve del claustro románico de Santo Domingo de Silos.

Otras preguntas que nos surgen a raíz de los investigado no las podemos responder por ahora. Algunas de ellas: ¿por qué esta iconografía no inspiró a otros artistas e influyo en otras obras posteriores?, ¿nos aporta algo lo descubierto para situar mejor la factura del relieve en el tiempo y, con ello, despejar sombras sobre el promotor del claustro?

Antonio Manuel Pérez, O.S.B.

\section{UN NUEVO LIENZO DE VAN DYCK RESTITUIDO: LA VIRGEN CON NIÑO $Y$ ÁNGELES JUNTO A UN ROSAL DE LA CASA DUCAL DE OSUNA}

La Virgen con Niño y ángeles junto a un rosal que restituimos a Van Dyck (fig. 1), es lienzo $(113 \times 113 \mathrm{~cm}$.) desconocido en los estudios y monografías más recientes del pintor. La referencia más próxima de la existencia de un original, es una copia antigua que publica el profesor Larsen (fig. 2) ${ }^{1}$. Con anterioridad, había catalogado el lienzo de la colección de los Osuna entre los

61 Ver nota 44.

${ }^{1}$ Lienzo, 110 x 92,5 cm. Suiza, Le Château, Monaz, Colección de la Señora André Muralt. Según el propietario, procede de la colección de Carlos X. [E. Larsen, The Paintings of Anthony van Dyck, II, 1988, p. 455, n A143a]. 